\title{
PRINCIPAIS CARACTERÍSTICAS DA PRODUÇÃO VOCAL DO DEFICIENTE AUDITIVO
}

\author{
Principal features of hearing impaired's voice production
}

Aline do Carmo Prado ${ }^{(1)}$

\begin{abstract}
RESUMO
Objetivo: descrever as principais características da produção vocal do deficiente auditivo, analisando quais os parâmetros da qualidade vocal são alterados pela deficiência da audição. Métodos: foi realizado um levantamento bibliográfico em Bibliotecas de Universidades e pesquisa em periódicos indexados na Base de dados Lilacs e Medline, dando ênfase aos estudos referentes ao tema desde 1971 até os estudos mais recentes. Resultados: os achados foram divididos em seis parâmetros: Características da Fala; Ressonância; Respiração; Parâmetros Acústicos; Aspectos Fonéticos e Tratamento Fonoaudiológico. Conclusão: com a revisão da literatura, foi possível identificar as principais características da produção vocal do deficiente auditivo. A discriminação e a realimentação auditivas são essenciais na produção da voz, e, no caso dos deficientes auditivos, como não desenvolvem o feedback auditivo, não conseguem ter controle sobre sua voz: (ressonância, intensidade, freqüência, articulação e respiração). A relevância da contribuição da Fonoaudiologia fica clara graças à garantia de melhora nas condições de comunicação desses indivíduos.
\end{abstract}

DESCRITORES: Audição; Distúrbios da Voz; Surdez; Qualidade da Voz

\section{INTRODUÇÃO}

A comunicação humana é de fundamental importância para a constituição de um meio social saudável. O principal meio de comunicação entre as pessoas é sem dúvida a fala. No entanto, alguns fatores podem acarretar prejuízo na sua produção. Dentre eles, estão as perdas de audição. Indivíduos, que, por alguma razão perderam a audição e apresentam apenas restos auditivos, enfrentam dificuldades para se comunicar oralmente ${ }^{1}$.

Sabemos que a falta de feedback auditivo é responsável pelas alterações na qualidade vocal e na produção da fala de indivíduos surdos.

A relação entre a articulação e a qualidade vocal nos deficientes auditivos é essencial para garantir a inteligibilidade de fala ${ }^{1,2}$.

Como voz e audição são aspectos que se relacionam e ouvir é uma atividade complexa e elabo-

(1) Fonoaudióloga; Lotada na Secretaria de Saúde do Rio de Janeiro e de Itaguaí; Especialização em Voz pelo CEFAC Saúde e Educação e Moacyr Sreder Bastos (MSB). rada, que envolve desde a detecção de estímulos sonoros pelos órgãos periféricos até sua interpretação pelo sistema auditivo nervoso central, pode-se dizer que a audição configura um fator importante para a manutenção de um padrão vocal adequado ${ }^{3}$.

Por apresentar um papel primordial no desenvolvimento da comunicação oral, a audição torna-se determinante para o desenvolvimento do padrão de emissão vocal, que acompanha o indivíduo por toda a vida e que é modificado conforme as experiências e vivências. Considerando o indivíduo surdo, pode-se dizer que a perda auditiva é um impedimento para o desenvolvimento da fala, pois restringe o indivíduo na recepção desta e reduz a habilidade do falante de monitorar sua própria fala ${ }^{4}$.

Autores afirmam que a audição é fundamental para o desenvolvimento da linguagem oral articulada da criança, para que essa adquira a mesma capacidade que o adulto tem de distinguir e reconhecer o significado dos sons, produzir e simbolizá-los através da fala ${ }^{3,5}$.

Nos primeiros meses de vida, mesmo sendo incapaz de ouvir sua própria voz, a criança deficiente auditiva chora e vocaliza da mesma maneira que uma criança ouvinte. Porém, à medida que 
envelhece, ocorre uma restrição em seu repertório relacionado à qualidade e à quantidade de sons, podendo não desenvolver o balbucio silábico. Já no final do primeiro ano, sua vocalização reduz-se ao que ela pode sentir, ou seja, sons guturais ou gritos agudos, semelhantes àqueles produzidos por bebês de um mês de vida ${ }^{6}$.

A criança surda não possui feedback auditivo, pois não consegue combinar os sons que ela faz em uma situação com aqueles que produzirá mais tarde, ou com sons produzidos por outras pessoas. Ela não desenvolve controle sobre voz, respiração e articulação ${ }^{1,3,4}$.

Acredita-se que no caso das crianças deficientes auditivas haveria, como no caso das crianças ouvintes, uma produção de sons diferenciada no início de sua vida, mas que, com a ausência das pistas auditivas a elas oferecidas, as produções sonoras decresceriam consideravelmente ${ }^{6}$.

Dessa maneira, em virtude da importância de se conhecer a respeito das conseqüências das alterações auditivas para a inteligibilidade da fala da criança surda, este estudo tem como objetivo descrever, por meio de pesquisa bibliográfica, as principais características da produção vocal do deficiente auditivo, analisando quais parâmetros da qualidade vocal que são alterados pela deficiência da audição.

\section{MÉTODOS}

Este trabalho propõe-se a apresentar sínteses dos trabalhos de diferentes autores que abordam a temática proposta neste estudo.

Para o cumprimento do objetivo deste presente trabalho, realizou-se Revisão Bibliográfica em artigos, livros, periódicos e dissertações.

Foi realizada a seleção de artigos em base de dados Lilacs e Medline, no período de 1971 até 2005. A escolha foi determinada, considerando-se a atualização dos artigos a serem estudados e sua relação com o tema do presente trabalho.

Os dados de revisão são apresentados nos resultados em forma de itens referentes a características de fala; ressonância; respiração; parâmetros acústicos; aspectos fonéticos e tratamento fonoaudiológico, agrupando-se e comparando-se idéias de autores e resultados de pesquisas, bem como, considerando-se a experiência de profissionais envolvidos com o tema.

\section{RESULTADOS}

O processo de comunicação oral é complexo: envolve aspectos acústicos, fisiológicos e proprioceptivos. A transmissão dos sons inicia-se com a formulação da mensagem no cérebro, ativando comandos neurais para a produção vocal, que é monitorada através de pistas auditivas, visuais e cinestésicas. Mas esse processo está prejudicado na comunicação oral dos surdos, que fazem esforço muscular excessivo durante a respiração e a fonação ${ }^{7}$.

Os resultados desta pesquisa estão divididos em seis itens:

\section{Características da Fala}

Alguns achados de pesquisas, com relação às características da fala de pessoas surdas e os conseqüentes efeitos na comunicação verbal, referem que as principais dificuldades são de sincronização, ritmo, altura, entoação, controle velar, articulação e qualidade ${ }^{8}$.

Os sujeitos deficientes auditivos apresentam grande esforço fonatório devido ao fluxo de ar deficiente e diminuição da pressão subglótica, perturbando o sistema aerodinâmico de vibração das pregas vocais, fazendo-se necessário maior esforço muscular ou aumento da tensão vocal para a fonação ${ }^{9}$.

Os problemas mais comuns da fala de indivíduos deficientes auditivos são: a omissão e ensurdecimento de consoantes, substituição de nasal por sua oral cognata, trocas de vogais, hipernasalidade, tendência para prolongar excessivamente as vogais, estridência, elevados valores de freqüência fundamental e irregularidades no ritmo da fala, sendo agravados com o aumento do grau da perda auditiva. Autores observaram que os deficientes auditivos têm preferência por vozes com freqüência fundamental grave por esta se apresentar de maneira mais clara, devido à riqueza de harmônicos ${ }^{9,10}$.

A explicação para a variabilidade existente na fala do surdo pode estar relacionada à extensão e ao tipo de perda auditiva, à idade em que ocorreu a perda, ao ambiente familiar e ao tipo de treino recebido ${ }^{11}$.

O desvio acentuado no registro e o controle de pitch estão, geralmente, associados a desvios proporcionais na loudness pelo fato da pressão respiratória subglótica servir como desencadeador da vibração das pregas vocais. A fala ininteligível pode ocorrer devido a problemas em diversas regiões onde deve haver controle do fluxo de ar como na válvula laríngea, na porta palatofaríngea, e em vários pontos de constrição criados dentro do trato vocal pelos movimentos de língua, lábios e mandíbula ${ }^{11}$.

Quando o problema ocorre, o falante não tem coordenação fina de respiração, fonação e articulação necessárias à fala. Como conseqüências, surgem problemas associados na prosódia, na intensidade vocal e no pitch, que não é modificado de maneira apropriada durante a fala ${ }^{11}$.

Destes fatos decorre uma qualidade vocal fraca, pela adução inadequada das pregas vocais, ou uma qualidade vocal tensa, pela força excessiva da musculatura laríngea durante a adução das pregas vocais. Quanto à ressonância faríngea, típica da voz 
dos deficientes auditivos, ela ocorre devido a uma retração da língua em direção à parede faríngea, podendo estar associada a um desvio de registro de pitch e a uma ressonância nasal excessiva.

A produção da fala é avaliada através dos sistemas: receptor, efetor, transmissor e sensor. O sistema sensor da fala é composto pelos sensores auditivos, tátil-cinestésico e visual, sendo responsáveis pelo controle automático e pela monitorização dos símbolos falados, assim como por suas dimensões fonatórias, ressonadora, articulatória e temporal ${ }^{12}$.

O sistema sensor auditivo, em circunstâncias normais, monitora o pensamento verbal e controla a efetiva produção do código verbo-acústico, tanto quanto suas dimensões de tempo e sonorização. Dependendo da idade do indivíduo, o sensor auditivo também faz uma importante contribuição ao controle e monitorização da articulação dos sons da fala. Quanto mais a idade do indivíduo se aproxima ou supera os sete ou oito anos, menor é a utilização do sensor auditivo no controle e monitoria da articulação. $\mathrm{O}$ sensor tátil-cinestésico coopera com o controle e monitoração da articulação efetiva, tornando-se aparentemente mais importante nesta atividade, logo após a maturação ${ }^{12}$.

Assim, deve-se desenvolver o máximo possível as sensações táteis-cinestésicas do aparelho fonador de indivíduos com deficiência auditiva severa, uma vez que estas encontram-se intactas ${ }^{13}$.

Os distúrbios vocais apresentados pelos deficientes auditivos variam de acordo com o tipo e o grau da perda auditiva, sendo que as perdas auditivas do tipo neurossensorial causam distúrbios vocais variados, tanto mais graves quanto maior a perda ${ }^{13}$.

Os tempos de emissão sonora apresentam-se reduzidos devido à dificuldade de coordenação pneumofônica e acentuado escape de ar nasal durante a fonação. A articulação tende a ser travada e imprecisa, e na maioria das vezes, esses indivíduos apresentam posição de língua abaixada e tracionada posteriormente na cavidade oral ${ }^{13}$.

\section{Ressonância}

A produção vocal dos surdos é geralmente acompanhada por uma alteração da ressonância faríngea excessiva do tipo cul-de-sac. E apesar de terem padrões de respiração corrente normais, apresentam dificuldades em realizar o início da fonação, sendo esta tardia no ciclo expiratório, com inspirações, em momentos impróprios, durante a fala encadeada, o que dificulta sua inteligibilidade de fala ${ }^{14}$.

\section{Respiração}

Essa dificuldade na coordenação respiratória para a produção da fala de deficientes auditivos é caracterizada por uma menor produção de sílabas por ciclo respiratório. Autores afirmam que o deficiente auditivo inspira em intervalos de somente uma, duas ou três palavras, expira mais sobre cada sílaba, quando comparado ao ouvinte ${ }^{15}$.

Esse esforço fonatório deve resultar do fluxo de ar insuficiente e da pressão subglótica, a qual perturba a aerodinâmica da vibração, necessitando de esforço muscular maior do que o normal e/ou aumentando a tensão vocal para concluir a fonação. Desta forma, a fala do deficiente auditivo se torna ineficiente fisicamente e por essa razão, mais cansativa. Ocorre um desperdício de esforço/energia que acaba resultando numa pobre inteligibilidade de fala ${ }^{15}$.

As características de excessiva ressonância faríngea incluem a neutralização da posição da língua, associada com a depressão da epiglote na hipofaringe ${ }^{16}$. Os sujeitos surdos podem apresentar desordem no esfíncter velofaríngeo, relacionado à ausência do controle auditivo durante a fonação ${ }^{17}$.

Estudos comparativos comprovaram que existem efeitos imediatos na qualidade vocal de indivíduos surdos que foram submetidos ao implante coclear, com ganhos na freqüência fundamental e na intensidade vocal, no pitch e na loudness, além de apresentarem maior controle na ressonância, devido aos efeitos do retorno auditivo. Mas é enfatizado que para que essas mudanças ocorram, torna-se imprescindível a estimulação e o treinamento auditivo, e em muitos casos, o trabalho fonoaudiológico para adequação do comportamento vocal ${ }^{18-20}$.

Crianças que recebem o implante coclear na fase pré-lingüística (ou seja, até o $3^{\circ}$ ano de vida), apresentam um melhor controle acústico sobre sua fala, normalizando sua freqüência fundamental e melhorando sua habilidade articulatória ${ }^{21}$. Contudo, comparados com crianças ouvintes da mesma idade, as crianças implantadas ainda estão longe de apresentarem as mesmas características dos parâmetros de pitch, intensidade, fluência e articulação (freqüência) ${ }^{22}$.

\section{Parâmetros Acústicos}

As medidas acústicas também são apresentadas em vários estudos, descrevendo os parâmetros acústicos referentes à qualidade vocal do deficiente auditivo, relacionando-os aos dados preceptivo-auditivos e fisiológicos, e permitindo a diferenciação entre articulação e produção de determinados sons.

Na análise dos parâmetros acústicos, o valor da média da freqüência fundamental (F0) na fala do sujeito surdo pode ser alto devido ao aumento de tensão das pregas vocais e do trato vocal, resultando em fechamento glótico excessivo ${ }^{8,23}$.

Quanto à análise dos formantes, a freqüência do primeiro formante (F1) está relacionada à abertura de oca e à altura de língua ${ }^{23}$. O sujeito deficiente auditivo apresenta instabilidade nos valores do primeiro formante, sugerindo a dificuldade de manutenção do trato vocal numa mesma postura articulatória, devido 
à postura de lábios, língua e mandíbula, o que interfere no efeito de ressonância e, conseqüentemente nas medidas de freqüência dos formantes ${ }^{13}$.

O parâmetro de freqüência do segundo formante (F2) está relacionado ao deslocamento antero-posterior de língua. Assim, quando há anteriorização da língua, o valor de F2 é maior, enquanto o valor menor de F2 indica a posteriorização de língua ${ }^{24}$.

Em estudos com deficientes auditivos, a diminuição da freqüência do segundo formante indica uma cavidade anterior maior, ou seja, a aproximação da língua com o palato duro é realizada em ponto mais posterior, havendo a constrição com a parede faríngea, mas há outros indivíduos que apresentam um aumento da freqüência do segundo formante, justificado pela língua abaixada e anteriorizada ${ }^{8}$.

\section{Aspectos Fonéticos}

Alguns estudos também foram feitos em relação aos aspectos fonéticos da fala da criança deficiente auditiva. O grau da perda auditiva, a quantidade de resíduos e o ganho funcional que o aparelho de amplificação sonora individual proporciona ao indivíduo, parecem influenciar no desempenho fonético de crianças com deficiência auditiva ${ }^{11,13}$.

As crianças ouvintes normais usualmente adquirem os fonemas básicos do sistema, isto é, vogais e consoantes, até por volta dos cinco anos de idade, aprendendo a relação entre significado e sons, como também a relação entre som e semelhança de movimentos articulatórios.

Em geral, as vogais são produzidas mais precisamente que as consoantes, devido ao seu poder fonético (energia sonora) e visibilidade na produção. Já as consoantes, devido à alta freqüência e alta intensidade, apresentam uma produção menos precisa do que as vogais ${ }^{11}$.

Um estudo da análise da produção fonética de crianças deficientes auditivas, através de um teste de linguagem infantil, demonstrou que os fonemas consonantais com pontos articulatórios mais anteriorizados, como os bilabiais e os alveolares, foram produzidos corretamente de forma mais freqüente pelas crianças deficientes auditivas do que os demais fonemas.

Neste estudo, os arquifonemas e os encontros consonantais apresentaram poucas ocorrências de produção adequada, ao contrário dos fonemas vocálicos, que foram produzidos de forma correta, mais freqüentemente que os fonemas consonantais.

As fricativas, em geral, são consideradas as mais fracas e agudas do português e de extrema dificuldade para o deficiente auditivo reconhecer em comparação com outros fonemas consonantais ${ }^{25}$.

A discriminação auditiva entre pares fricativos surdos e sonoros é considerada de difícil execução, precisando da informação adicional e suplementar da leitura orofacial, onde a produção correta é facilitada quando a criança já teve contato anterior com a palavra a que o fonema pertence em situações em que ela tinha tido acesso a pistas visuais na fala do interlocutor ${ }^{11}$.

Tratamento Fonoaudiológico

Vários são os estudos que pesquisaram os meIhores métodos e técnicas para a terapia vocal do deficiente auditivo. Os objetivos a serem trabalhados são: nível de altura modal, ressonância, controle da intensidade da fala, ritmo e velocidade de fala ${ }^{26}$

Este mesmo autor descreveu uma lista de dez passos a serem seguidos na terapia com deficientes auditivos: $1^{\circ}$ ensinar o parâmetro correto que queremos trabalhar; $2^{\circ}$ identificar no outro um aspecto vocal inadequado; $3^{\circ}$ reconhecer no outro o uso vocal correto; $4^{\circ}$ começar a modificar e controlar o seu próprio comportamento vocal; $5^{\circ}$ diferenciar a produção vocal correta da incorreta; $6^{\circ}$ identificar locais e situações em que usa o comportamento vocal incorreto; $7^{\circ}$ identificar situações em que seu comportamento é aceitável; $8^{\circ}$ verificar se está havendo um maior ou menor uso do novo hábito vocal; $9^{\circ}$ verificar se a utilização desse novo hábito vocal ocorre muitas vezes e $10^{\circ}$ constatar a utilização sistemática do novo hábito vocal.

Propõe como procedimentos básicos, o treinamento auditivo, o ensino do uso correto da voz e a automatização do uso correto da voz. Sendo que esses objetivos devem ser adaptados às necessidades de cada criança para auxiliar a automatização e produção correta da voz ${ }^{26}$.

Em outro estudo, é sugerido que se desenvolva o máximo possível as sensações táteis-cinestésicas do aparelho fonador de indivíduos com deficiência severa, uma vez que estas encontram-se intactas ${ }^{13}$.

Assim, o plano terapêutico deve ser composto por treinamento prévio de discriminação auditiva, conscientização da respiração associada à fonação, adequação da postura corporal, movimentos adequados dos articuladores (mandíbula, lábios, e língua), livre excursão da laringe no pescoço, adequação da intensidade vocal ao ambiente. Sugere ainda desenvolver noções de ritmo, o sentido tátil da fala, observando-se adequação da ressonância. E, por fim, deve ser feita uma orientação familiar ${ }^{13}$.

Com o objetivo de verificar o efeito de um método de terapia de voz na qualidade vocal e na inteligibilidade da fala de indivíduos surdos, um recente estudo resultou em melhor qualidade vocal, melhor inteligibilidade da fala, redução da freqüência máxima e das médias dos índices de perturbação da freqüência fundamental em curto prazo (jitter e shimmer), redução da energia de ruído glótico e aumento dos tempos máximos de fonação das vogais prolongadas $(\mathrm{a}, \mathrm{i}, \mathrm{u})$ e dos sons fricativos $(\mathrm{s}, \mathrm{z})^{27}$. 
O método constou de exercícios e atividades com jogos computadorizados que proporcionavam feedback visual para a emissão da fala, permitindo ao indivíduo controlar a freqüência e a intensidade, fixados pelo fonoaudiólogo.

\section{DISCUSSÃO}

Sabemos que a criança desenvolve-se através de influências múltiplas de fatores: o biológico, o afetivo, o sócio-econômico, o comportamental, entre outros.

De acordo com os resultados desta revisão de literatura, foi possível constatar que a criança com perda auditiva tem o fator biológico comprometido no nível auditivo, o que a impede de adquirir a língua pelo processo natural de ouvir e de falar. Não desenvolverá, portanto, a linguagem oral por si só ${ }^{1}$.

Como afirmado por alguns autores, a criança com perda auditiva apresentará tanto maiores dificuldades na aprendizagem da línguagem oral, quanto maior for o grau da perda ${ }^{11}$.

A qualidade vocal do deficiente auditivo também é alvo de discussões, uma vez que para sua produção é necessária à monitorização dos diversos parâmetros envolvidos na voz.

Os resultados obtidos através de pesquisas acústicas e análises perceptivo-auditivas destacaram características relativas à qualidade de voz, ressonância, articulação e pitch. Em relação à qualidade de voz, são descritas: a voz soprosa, pela dificuldade do controle da musculatura intrínseca da laringe; a voz tensa, devido ao fechamento glótico excessivo, e a voz áspera, interligada à incidência de tensão laríngea e à elevação da postura da laringe $^{3,8,23,27}$.

A ressonância é descrita na literatura como hiponasal, hipernasal, "cul-de-sac" ou faríngea, porém há destaque para a percepção de nasalidade, que está relacionada à alteração do ritmo da fala, à inteligibilidade de fala e à percepção auditiva prejudicadas $^{14,17,27}$.

Deve-se destacar que, quanto à articulação, esta é descrita tanto por movimentos exagerados da mímica facial, quanto por movimentos de língua, de mandíbula e dos lábios minimizados ${ }^{13}$.

Relacionado ao parâmetro pitch, a maioria dos autores o descrevem como agudo, mas alguns o consideram grave, quando associado à língua posteriorizada.

As medidas acústicas para a voz do deficiente auditivo também foram apresentadas em vários estudos, sendo uma das justificativas, para estarem alteradas, o fato de permitirem a diferenciação entre a articulação e a produção de determinados sons entre grupos de falantes ${ }^{19,23,27}$.

A definição das características vocais está relaci- onada tanto com a freqüência fundamental $(F)$ e harmônicos, quanto com os fatores dinâmicos da fala, como a transição de gestos que modificam uma posição articulatória em outra ${ }^{23}$.

Na população com deficiência de audição severa e profunda, há o aumento da $\mathrm{F}_{\text {o }}$ média, em decorrência da ausência de feedback acústico e da hiperfunção laríngea ${ }^{3}$.

Nos sujeitos deficientes auditivos a relação entre a articulação e a qualidade vocal é relatada como essencial para garantir a inteligibilidade de fala ${ }^{1,2}$

É pertinente afirmar, a partir deste estudo, que os desafios, na tentativa de se compreender o mecanismo utilizado para a produção da fala e o que fazer para propiciar a melhora dessa produção nos indivíduos surdos, são tão grandes, que vários estudos e pesquisas com avanços tecnológicos surgiram para possibilitar * melhor acompanhamento e avaliação da voz e da fala e maior compreensão dos gestos laríngeos produzidos pelos indivíduos ${ }^{23,27}$.

A fala ininteligível encontrada no deficiente auditivo pode ocorrer por problemas que vão desde a falta de controle respiratório a movimentos inadequados de língua, lábios e mandíbula. Decorrentes destes, surgirão problemas associados a prosódia, intensidade vocal e pitch, que não são modificados adequadamente durante a fala ${ }^{10}$.

A partir daí teremos duas maneiras de produção da fala: ou o indivíduo fará uso de uma qualidade vocal do tipo aspirada/fraca, resultante de uma adução inadequada das pregas vocais, ou ele produzirá uma voz com qualidade vocal tensa por produzir força excessiva da musculatura laríngea durante a fonação. Como falta feedback auditivo para esses indivíduos, é comum que eles produzam mais esforço vocal para se fazer entender durante a comunicação oral. Geralmente estes esforços são centrados em exercícios de articulação, por ser o aspecto da fala mais visível e de fácil detecção. Isso acaba por levar a uma articulação exagerada e, conseqüentemente, a uma fala menos inteligível ${ }^{5,11,13}$. Pode-se afirmar que as pistas acústicas de intensidade e faixa de freqüência na produção dos fonemas são fatores fundamentais no desenvolvimento fonético da criança portadora de deficiência auditiva. O grau da perda auditiva, a quantidade de resíduos e o ganho funcional, que o aparelho de amplificação sonora individual proporcionam ao indivíduo, parecem influenciar no desempenho fonético de crianças deficientes auditivas ${ }^{19}$.

As pistas visuais que o interlocutor proporciona na sua produção articulatória dos fonemas parecem atuar como um importante fator no desenvolvimento fonético, mas não podem ser considerados como a base para a aquisição fonética das crianças surdas ${ }^{11,19}$.

É pertinente comentar que durante a realização deste estudo pôde-se verificar que a voz e a fala do surdo estão comprometidas em termos de qualidade e não só 
de amplificação. Sendo assim, faz-se necessário um trabalho conjunto entre fonte e filtro vocal ${ }^{13}$.

Com relação à intervenção fonoaudiológica, ficou evidente, na literatura pesquisada, sua importância.

Através desses achados, verifica-se que a alteração do surdo não se restringe somente à falta de audição, mas envolve todos os comprometimentos conseqüentes da perda auditiva. Isso nos remete à importância de pesquisas científicas, uma vez que permitirão a ampliação e a atualização de conhecimentos de profissionais das áreas afins, a fim de se investigar e descobrir novas formas de minimizar e/ou prevenir maiores complicações para o indivíduo.

\section{CONCLUSÃO}

Neste estudo bibliográfico, ficou evidente que a discriminação e a realimentação auditiva ocupam uma posição peculiar na produção vocal. E, no caso dos surdos, a alteração no feedback auditivo é o principal impedimento para a monitorização dos parâmetros vocais alterados.

Como foi visto, no caso das crianças deficientes auditivas, haveria, como no caso das crianças ouvintes, uma produção diferenciada de sons no início de sua vida, mas que, com a ausência das pistas auditivas a elas oferecidas, as produções sonoras decres- ceriam consideravelmente.

Sem o feedback auditivo, a criança não combina os sons e não desenvolve controle sobre voz, respiração e articulação. Da mesma forma, sem o fluxo de ar suficiente, o surdo faz grande esforço fonatório, apresentando dificuldade de entoação, freqüência, intensidade, prosódia, ritmo, articulação, ressonância e qualidade vocal.

Este fato é altamente representativo no trabalho de voz com o deficiente auditivo, pois o paciente literalmente não sabe o que está fazendo quando * produz a fonação. Evidencia-se, portanto, a contribuição da fonoaudiologia neste trabalho.

Poderíamos então inferir que no processo terapêutico, que envolve a voz do surdo, as percepções auditiva, táteis e cinestésicas são essenciais, uma vez que esses indivíduos necessitam desenvolver a capacidade de monitorizar sua fala para uma produção vocal mais eficiente.

A partir dessas reflexões, observamos que a literatura sobre as características da voz de indivíduos surdos é vasta, não ocorrendo o mesmo com relação aos achados acústicos. A junção desses conhecimentos aos recursos de terapia revela a possibilidade da melhora da qualidade vocal e de ajustes fonatórios, favorecendo maior inteligibilidade da fala desses indivíduos.

\begin{abstract}
Purpose: to describe the principals characteristics of hearing impaired voice production, and analyze which aspects of vocal quality are modified by deafness. Methods: searching the vast published literature, by a survey* in public libraries and search in indexed periodicals in Lilacs and Medline, emphasizing the studies which are related to the subject since 1971 until most recent studies. Results: The results have been separated into* six categories: speech features; resonance; breathing, acoustic features; phonetic aspects and speech therapy treatment. Conclusion: It was possible to identify the principal features of impaired * hearing voice production. The hearing feedback and discrimination are essential for voice production, not developed in hearing impaired people, so they do not have ability to control their voice (resonance, intensity, frequency, pronunciation and breathing). The relevance of Speech Therapy is clear, as it guarantees the improvement of these communication conditions in these subjects.
\end{abstract}

KEYWORDS: Voice; Hearing; Voice Disorders; Deafness; Voice Quality

\section{REFERÊNCIAS}

1.Bento RF, Brito Neto R, Castillo AM, Gómez VG, Giorgi SB, et al. Resultados auditivos com o implante coclear multicanal em pacientes submetidos a cirurgia no Hospital das Clínicas da Faculdade de Medicina da Universidade de São Paulo. Rev Bras Otorrinolaringol. 2004; 70(5):632-7.

2.Tabith JA. Alguns aspectos da voz e da morfofisiologia laríngea em deficientes auditivos severos e profundos. Rev Bras Otorronolaringol. 1997; 63(4):319-26.

3.Buosi MMB. A interdependência entre habilidades auditivas e produção vocal. Fono Atual. 2002; 5(20):53-7.

4. Cavadas M, Pereira L, Behlau M. Disfonia infantil e processamento auditivo central. In: Valle MGM. Voz: diversos enfoques em fonoaudiologia. Rio de Janeiro: 
Revinter; 2002. p. 99-109.

5.Pereira KL, Garcia VL. Análise da produção fonética de crianças deficientes auditivas. Rev CEFAC. 2005; 7(4):473-82.

6.Lima MCMP, Gonçalves VMG. Integração dos sistemas auditivos e motor da fala em lactentes e ouvintes surdos. In: Marchesan IQ, Zorzi JL, Gomes ICD. Tópicos em fonoaudiologia. v. 3. São Paulo: Lovise; 1996. p. 411-65.

7.Levitt $\mathrm{H}$. Speech production and yhe deaf child. In: Speech for the deaf child. Washington: Alexander Graham Bell Association for the Deaf; 1971. p. 59-83.

8.Nickerson RS. Characteristics of the speech of the deaf persons. Volta Rev. 1975; 77:342-62.

9.Forner LL, Hixon TJ. Respiratory kinematics in profoundly hearing-impaired speakers. J Speech Hear Res. 1977; 20(2):373-408.

10. Calvert DR, Silverman SR. Speech and deafness. Washington: Alexander Graham Bell Association for the Deaf; 1978. 243 p.

11. Subtelny JD, Whitehead RL, Orlando NA. Description and evaluation of an instructional program to improve speech and voice diagnosis of the hearing impaired. Volta Rev. 1980; 85-95.

12. Mysak ED. Avaliação e diagnóstico das desordens dos sistemas da fala. In: Mysak ED. Patologias dos sistemas da fala. 2. ed. São Paulo: Atheneu; 1998. p. 53-87.

13. Pinho S. Proposta de avaliação de voz no deficiente auditivo. Pró-Fono. 1990; 2:17-9.

14. Boone $D, M c F a r l a n e ~ S$. The voice and voice therapy. 4. ed. New Englewood Cliffs: New Jersey: Pentice Hall; 1994. 244 p.

15. Borges RHM. Avaliação de voz em deficientes auditivos: uma análise crítica. In: Ferreira LP. Dissertando sobre voz. São Paulo: Pró-Fono; 1998; p. 150-71.

16. Subtelny JD, Whitehead RL, Samar VJ. Spectral study of deviant resonance in the speech of women who are deaf. J Speech Hear Res. 1992; 35(3):574-9. 17. Ysunza A, Vazquez MC. Velopharyngeal sphincter physiology in deaf individuals. Cleft Palate Craniofac J. 1993; 30(2):141-3.

18. Leder SB, Spitzer JB, Kirchner JC. Immediate effects of cochlear implantation on voice quality. Arch Otorhinolaryngol. 1987; 244(2):93-5.

19. Lane H, Wozniak J, Perkell J. Changes in voiceonset time in speakers with cochlear implants. J Acoust Soc Am. 1994; 96(1):56-64.

20. Perrin E, Berger-Vachon VC, Topouzkhanian A, Truy E, Morgon A. Evaluation of cochlear implanted children's voices. Int J Pediatr Otohinolaryngol. 1999; 47(2):181-6.

21. Seifert E, Oswald M, Bruns U, Vischer M, Kompis $M$, Haeusler R. Changes of voice and articulation in children with cochlear implants. Int J Pediatr Otorhinolaryngol. 2002; 66(2):115-23.

22. Higgins MB, McCleary EA, Carney AE, Schulte L. Longitudinal changes in children's speech and voice physiology after cochlear implantation. Ear Hear. 2003; 24(1):48-70.

23. Camargo Z. Da fonação à articulação: princípios fisiológicos e acústicos. Fonoaudiol Bras. 1999; 2(2):14-9.

24. Cukier S, Camargo Z. Abordagem da qualidade vocal em um falante com deficiência auditiva: aspectos acústicos relevantes do sinal de fala. Rev CEFAC. 2005; 7(1):93-101.

25. Russo I, Behlau M. Percepção da fala: análise acústica do português brasileiro. São Paulo: Lovise; 1993.

26. Wilson DK. Voice problems of children. 3. ed. Baltimore: Williams \& Wilkins; 1987.400 p.

27. Bommarito $S$. O efeito de um método de terapia de voz na qualidade vocal e na inteligibilidade da fala de indivíduos surdos [mestrado]. São Paulo (SP): Universidade Federal de São Paulo; 2002. 122 p.

Endereço para correspondência:

Rua José Piragibe, 118

Rio de Janeiro - RJ

CEP: $23050-140$

Tel.: (21) 33946325 / 97397259

e-mail: alinecarmo@uol.com.br 